\title{
Ground State Modulation in Nickel(III) Chemistry by Controlling Axial Ligation in Complexes with $\mathrm{N}_{3} \mathrm{O}_{2}$ Pentadentate Ligands
}

\author{
Dora Pinho, ${ }^{[a]}$ Paula Gomes, ${ }^{[a][+]}$ Cristina Freire, ${ }^{*[a]}$ and Baltazar de Castro*[a]
}

Keywords: EPR spectroscopy / Nickel / Redox chemistry / Schiff bases / Voltammetry

The accessibility of the +3 oxidation state for nickel(II) complexes with $\mathrm{N}_{3} \mathrm{O}_{2}$ pentadentate Schiff base ligands prepared by condensation of naphthaldehyde or 3,5-dichlorosalicylaldehyde with triamines (Scheme 1) has been assessed in several solvents, by combining cyclic voltammetry and EPR spectroscopy of the oxidised metal complexes. The data show that trien/Metrien-based ligands act in pentadentate fashion and allow for the stabilisation of electrochemically and chemically generated nickel(III) complexes in all solvents used. The complexes, formulated as $\left[\mathrm{Ni}^{\mathrm{III}} \mathrm{L}(\mathrm{solv})\right]^{+}$, are low-spin and have a ${ }^{2} \mathrm{~A}_{1},\left[a \mathrm{~d}_{\mathrm{z}}{ }^{2}+b \mathrm{~d}_{\mathrm{x}^{2}-\mathrm{y}^{2}}{ }^{2}\right.$, ground state, with $a \geq b$. For dien-based ligands, steric constraints prevent coordination of the amine nitrogen atom of the pentadentate ligand to the metal centre, thus enforcing a fourfold coordination on the ligand. The resulting complexes can be oxidised to nickel(III) species, but only when using iodine as oxidant, in $\mathrm{DMF}$ or $\left(\mathrm{CH}_{3}\right)_{2} \mathrm{SO}$. The complexes are formulated as
$\left[\mathrm{Ni}^{\mathrm{III}} \mathrm{L}(\mathrm{solv})_{2}\right]^{+}$, and are low-spin and have a ${ }^{2} \mathrm{~A}_{1},\left[a \mathrm{~d}_{\mathrm{z}}{ }^{2}+b\right.$

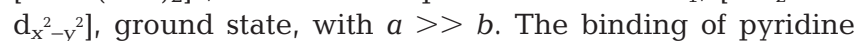
and cyanide ion to $\mathrm{Ni}^{\mathrm{III}}$ trien/Metrien-based complexes was studied by EPR. The data obtained show that these polydentate ligands provide a flexible coordination sphere, and that by varying the ratio equatorial/axial ligand field it is possible to obtain $\mathrm{Ni}^{\mathrm{III}}$ in three different ground states. For pyridine adducts, the same ground state as the parent complex was observed with Metrien-based ligands, while for trien-based ligands an inverted ground state $\left({ }^{2} \mathrm{~A}_{1},\left[a \mathrm{~d}_{\mathrm{z}}{ }^{2}+b \mathrm{~d}_{\mathrm{x}-\mathrm{y}}{ }^{2}\right]\right.$, with $a<<b$ ) was observed, as the latter provides a higher axial ligand field. On the other hand, coordination of cyanide adducts induces a change in the principal molecular axis of the $\mathrm{Ni}^{\mathrm{III}}$ complexes, in which the cyanide ions occupy equatorial positions, and in which a ${ }^{2} \mathrm{~A}_{1},\left[a \mathrm{~d}_{\mathrm{z}}{ }^{2}+b \mathrm{~d}_{\mathrm{x}^{2}-\mathrm{y}^{2}}{ }^{2}\right.$, ground state, with $a>>b$, is observed.

\section{Introduction}

We have become interested in the redox chemistry of nickel(II) complexes with $\mathrm{N}_{2} \mathrm{O}_{2}$ Schiff ligands, obtained by condensation of salicylaldehyde/naphthaldehyde with diamines, and on the characterisation of the oxidised/reduced species. ${ }^{[1-10]}$ These tetradentate ligands are noninnocent in oxidation and reduction processes, and their solution oxidative behaviour is intricate, as both the metal centre and the ligand can be the final electron donor. It has been found that, although ligands with substantial $\pi$ delocalisation favour ligand oxidation, the solvent plays a determining role in controlling the final oxidation site, ${ }^{[1-8]}$ since oxidation of square-planar $\mathrm{Ni}^{\mathrm{II}}$ complexes proceeds with the simultaneous coordination of two solvent molecules. Consequently, complexes are oxidised to $\mathrm{Ni}^{\mathrm{III}}$ only in strong donor solvents, such as DMF and $\left(\mathrm{CH}_{3}\right)_{2} \mathrm{SO}$, whereas in poorly coordinating solvents, ligand oxidation takes place and the products are radical $\mathrm{Ni}^{\mathrm{II}}$ species ${ }^{[2,3,11]}$ or $\mathrm{Ni}^{\mathrm{II}}$ conducting polymers. ${ }^{[7,8]}$

Nickel(III) complexes with these Schiff ligands are sixcoordinate, with the polydentate ligand defining the equatorial plane and with the two elongated axial bonds occu-

[a] CEQUP/Departamento de Química, Faculdade de Ciências, Universidade do Porto,

4169-007 Porto, Portugal

[ः] Present address: CIQ(UP), Faculdade de Ciências, Universidade do Porto, 4169-007 Porto, Portugal pied by solvent molecules. The complexes are invariably low-spin, with a ${ }^{2} \mathrm{~A}_{1}\left[a \mathrm{~d}_{z^{2}}+b \mathrm{~d}_{x^{2}-y^{2}}\right]$ ground state, with $a$ $>>b .^{[1-6]}$ Axial bonds are labile, and substitution of solvent molecules by Lewis bases (such as pyridines, imidazole, phosphanes, and $\mathrm{CN}^{-}$) is easily accomplished. ${ }^{[1-6]}$ All these adducts have the same ground state as the parent $\mathrm{Ni}^{\mathrm{III}}$ complex, but their decomposition to nickel(II) species is much faster.

In order to reduce solvent influence on the accessibility of the +3 oxidation state in nickel complexes with Schiff bases derived from salicylaldehyde/naphthaldehyde, and thus to increase the range of solvents in which $\mathrm{Ni}^{\mathrm{III}}$ complexes can be obtained, we have synthesised similar ligands, but ones in which the diamines bear a nitrogen donor atom, thereby constituting potential pentadentate ligands. By changing the donor ability of the inserted nitrogen atom and the length of the carbon imine bridge, it is possible to control the structures of the complexes and the reactivities of the metal centres.

In this work, we report the characterisation, using EPR and electronic spectroscopy, of several electrochemically and chemically generated nickel(III) complexes with $\mathrm{N}_{3} \mathrm{O}_{2}$ pentadentate Schiff base ligands, prepared by condensation of naphthaldehyde or 3,5-dichlorosalicylaldehyde with a triamine (Scheme 1). The accessibility of the +3 oxidation state to nickel(II) complexes was assessed by cyclic voltammetry in several solvents. EPR was the technique of choice for studying nickel complex oxidation, as this technique allows a clear distinction to be made between metal-based 
and ligand-based oxidised species. The characterisation of nickel(III) species has revealed that these pentadentate ligands make the nickel(III) complexes less solvent-dependent, and thus it was possible to observe $\mathrm{Ni}^{\mathrm{iII}}$ oxidised species in methanol, a solvent with moderate coordinating ability. Moreover, by replacing the axially bound atoms with increasingly strong donors, it was possible to demonstrate that the ligands were very flexible and to generate nickel(III) complexes with different ground states, by controlling the ratio of axial to equatorial ligand fields.

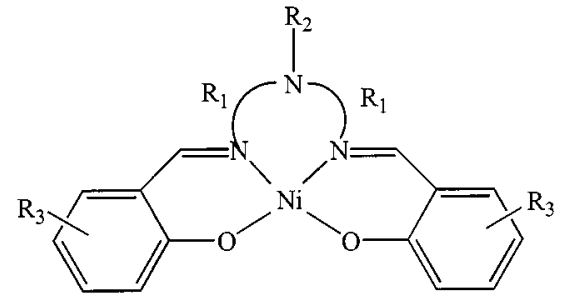

$\begin{array}{ccccc} & \mathrm{R}_{1} & \mathrm{R}_{2} & \mathrm{R}_{3} & \\ 1 & -\mathrm{CH}_{2}-\mathrm{CH}_{2^{-}} & \mathrm{H} & \\ 2 & -\mathrm{CH}_{2}-\mathrm{CH}_{2^{-}} & \mathrm{H} & 3,5-\mathrm{Cl}_{2} & {\left[\mathrm{Ni}\left(\mathrm{Cl}_{4} \text { saldien) }\right]\right.}\end{array}$

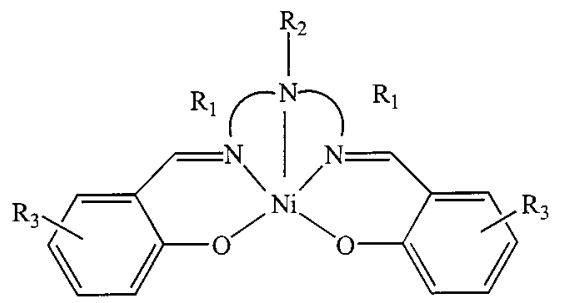
3

$$
-\mathrm{CH}_{2}-\mathrm{CH}_{2}-\mathrm{CH}_{2-}^{-} \quad \mathrm{H}
$$

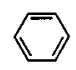
[Ni(naptrien)]
4

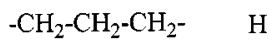
$3,5-\mathrm{Cl}_{2}$
$\left[\mathrm{Ni}\left(\mathrm{Cl}_{4}\right.\right.$ saltrien $\left.)\right]$
$5 \quad-\mathrm{CH}_{2}-\mathrm{CH}_{2}-\mathrm{CH}_{2}-\quad \mathrm{CH}_{3}$

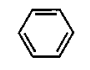
[Ni(napMetrien)]
6
$-\mathrm{CH}_{2}-\mathrm{CH}_{2}-\mathrm{CH}_{2}-$
$\mathrm{CH}_{3}$
$3,5-\mathrm{Cl}_{2}$
[Ni( $\mathrm{Cl}_{4}$ salMetrien $\left.)\right]$

Scheme 1

\section{Results and Discussion}

\section{Structural and Electronic Data for Nickel(II) Complexes}

Like those of similar Schiff base complexes, ${ }^{[12-15]}$ the electronic spectra of nickel(II) complexes 1-6 can be grouped into two sets on the basis of the size of the imine bridge: complexes with dien-based ligands and with trien- and Metrien-based ligands.

Spectra of complexes with dien bridges $(\mathbf{1}, \mathbf{2})$ are very similar and exhibit high intensity bands in the range $380-460 \mathrm{~nm}$, attributed on the basis of their extinction coefficients to CT and intraligand electronic transitions. The lack of any observed d-d bands above $\lambda \approx 500 \mathrm{~nm}$, since they must be masked by the high intensity bands, implies a four-coordinate environment for the nickel centre. ${ }^{[12,15]}$ Thus, the amine nitrogen atom of the bridge is not bound to the metal centre and the ligand acts in tetradentate fashion in a cis conformation.

The crystal structure of $\left[\mathrm{Ni}\left(\mathrm{Cl}_{4}\right.\right.$ salMetrien $\left.)\right](6)$ has been determined ${ }^{[16]}$ the nickel atom was found to be in a distorted octahedral coordination geometry, with the pentadentate ligand acting effectively as an $\mathrm{N}_{3} \mathrm{O}_{2}$ donor and with a solvent molecule (1,4-dioxane) occupying the remaining coordination site, trans to the amine nitrogen atom. Electronic spectra are consistent with this geometry, exhibiting two d-d bands in the near-infrared region, $\lambda_{\max }(\varepsilon)=$ $1159 \mathrm{~nm} \quad\left(8 \quad \mathrm{dm}^{3} \mathrm{~mol}^{-1} \mathrm{~cm}^{-1}\right)$ and $966 \mathrm{~nm} \quad(10$ $\mathrm{dm}^{3} \mathrm{~mol}^{-1} \mathrm{~cm}^{-1}$ ), one low-intensity d-d band in the visible region, $\lambda_{\max }(\varepsilon)=568 \mathrm{~nm}\left(36 \mathrm{dm}^{3} \mathrm{~mol}^{-1} \mathrm{~cm}^{-1}\right)$, and highintensity bands (CT and intraligand) at wavelengths $<$ $500 \mathrm{~nm}$.

The similarity between the electronic spectra of $\mathbf{6}$ in the solid state and those of the other trien- and Metrien-based complexes, for which no crystal data are available, is taken to imply that the latter complexes may have similar structures. The ligands are thus assumed to act as pentadentate and to bind in a trans conformation. Furthermore, the similarity of the electronic data for complexes 1-6 in the solid state and in DMF solution additionally suggests that, in solution, the complexes may have structures that resemble those in the solid, with the sixth position occupied by a solvent molecule.

For complexes with the same aldehyde moieties, those with trien bridges have the d-d bands at higher energies than those with Metrien bridges. This hypsochromic shift reflects the relative position of secondary and tertiary amine nitrogen atoms in the spectrochemical series. ${ }^{[17]}$ On the other hand, the d-d bands of complexes derived from naphthaldehyde are red-shifted relative to those of the corresponding chlorosalicylaldehyde derivatives, implying that the latter are stronger ligands in the nickel(II) complexes studied.

\section{Cyclic Voltammetry of Nickel(II) Complexes}

Cyclic voltammetric data in $\mathrm{MeOH}$, DMF, and $\left(\mathrm{CH}_{3}\right)_{2} \mathrm{SO}$ are presented in Table 1 . As with the spectroscopic data, the electrochemical responses can be grouped into two sets: complexes with dien bridges, which are irreversibly oxidised in all solvents, and complexes with trien and Metrien bridges, for which one oxidation process is normally observed in the potential range studied.

For dien-based complexes, scan rates up to $1.0 \mathrm{~V} \mathrm{~s}^{-1}$ were used. For high sweep rates only one incipient anodic wave could be observed for [Ni(napdien)], and this only in DMF and in $\left(\mathrm{CH}_{3}\right)_{2} \mathrm{SO}$. Furthermore, when chemically oxidised with iodine, all dien-based complexes exhibit $\mathrm{Ni}^{\mathrm{III}} \mathrm{EPR}$ signals in frozen DMF and $\left(\mathrm{CH}_{3}\right)_{2} \mathrm{SO}$ solutions (see below). These observations suggest that a very fast chemical decomposition of the electrogenerated nickel species may occur in these strongly coordinating solvents after charge transfer, as the carbon backbone of the imine bridge is long enough to induce significant tetrahedral distortions in the com- 
Table 1. Cyclic voltammetric results for NiL complexes in $\mathrm{CH}_{3} \mathrm{OH}$, DMF and $\left(\mathrm{CH}_{3}\right)_{2} \mathrm{SO}\left(0.1 \mathrm{~mol} \cdot \mathrm{dm}^{-3} \mathrm{NEt}_{4} \mathrm{ClO}_{4}\right)$ at $25{ }^{\circ} \mathrm{C}^{[\mathrm{a}]}$

\begin{tabular}{|c|c|c|c|c|c|c|c|c|c|c|c|c|c|c|c|}
\hline \multirow[b]{2}{*}{ Complex } & \multicolumn{5}{|c|}{$\mathrm{CH}_{3} \mathrm{OH}$} & \multicolumn{5}{|c|}{$\mathrm{dmf}$} & \multicolumn{5}{|c|}{$\left(\mathrm{CH}_{3}\right)_{2} \mathrm{SO}$} \\
\hline & $E_{\mathrm{pe}}$ & $E_{\mathrm{pc}}$ & $\Delta E$ & $E_{1 / 2}$ & $i_{\mathrm{pe}} / i_{\mathrm{pe}}$ & $E_{\mathrm{pa}}$ & $E_{\mathrm{pc}}$ & $\Delta E$ & $E_{1 / 2}$ & $i_{\mathrm{p}} /{ }_{\mathrm{pu}}$ & $E_{\mathrm{pa}}$ & $E_{\mathrm{pe}}$ & $\Delta E$ & $E_{1 / 2}$ & $i_{\mathrm{p}^{2}} / i_{\mathrm{pa}}$ \\
\hline [Ni(napdien)] & & & {$[\mathrm{b}]$} & & & & & {$[\mathrm{b}]$} & & & & & [b] & & \\
\hline$\left[\mathrm{Ni}\left(\mathrm{Cl}_{4}\right.\right.$ saldien $\left.)\right]$ & & & {$[\mathrm{b}]$} & & & & & {$[\mathrm{b}]$} & & & & & {$[\mathrm{b}]$} & & \\
\hline [Ni(naptrien)] & & & {$[\mathrm{b}]$} & & & 0.50 & 0.42 & 0.08 & 0.46 & 0.94 & 0.45 & 0.36 & 0.09 & 0.40 & 0.93 \\
\hline$[\mathrm{Ni}($ napMetrien) $] \quad$ (5) & & & {$[\mathrm{b}]$} & & & 0.53 & 0.46 & 0.07 & 0.50 & 0.99 & 0.46 & 0.40 & 0.06 & 0.43 & 1.00 \\
\hline$\left[\mathrm{Ni}\left(\mathrm{Cl}_{4}\right.\right.$ saltrien $\left.)\right]$ & 0.71 & 0.61 & 0.10 & 0.66 & $0.78^{[\mathrm{c}]}$ & 0.77 & 0.70 & 0.07 & 0.74 & $0.76^{[\mathrm{c}]}$ & 0.74 & 0.63 & 0.11 & 0.68 & $0.82^{[c]}$ \\
\hline$\left[\mathrm{Ni}\left(\mathrm{Cl}_{4}\right.\right.$ salMetrien $\left.)\right](6)$ & 0.73 & 0.63 & 0.10 & 0.68 & $0.78^{[\mathrm{c}]}$ & 0.90 & 0.67 & 0.23 & 0.78 & $0.83^{[\mathrm{c}]}$ & 0.78 & 0.67 & 0.11 & 0.72 & $0.77^{[\mathrm{c}]}$ \\
\hline
\end{tabular}

${ }^{\text {[a] }}$ All potentials in $\mathrm{V}$ vs. $\mathrm{Ag} / \mathrm{AgCl}\left(1 \mathrm{~mol} \cdot \mathrm{dm}^{-3} \mathrm{NaCl}\right)$. Solute concentration about $10^{-3} \mathrm{~mol} \cdot \mathrm{dm}^{-3} ;$ scan rate: $0.50 \mathrm{~V} \cdot \mathrm{s}^{-1} ; \Delta E=E_{\mathrm{pa}}-\mathrm{E}_{\mathrm{p} c}$; $E_{1 / 2}=1 / 2\left(E_{\mathrm{pa}}+E_{\mathrm{pc}}\right) ; E_{\mathrm{pa}}$ and $E_{\mathrm{pc}}$ are the anodic and cathodic peak potentials, respectively. Under the conditions used, $E_{1 / 2}\left(\mathrm{Fc}{ }^{+} / \mathrm{Fc}\right)$ is

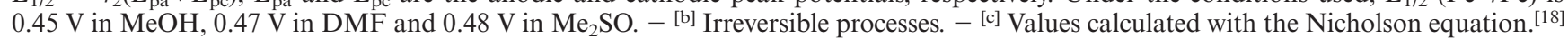

plexes and to make it difficult for solvent molecules to coordinate to the metal centre, thus hindering stabilization of the +3 oxidation state. ${ }^{[2,3,11]}$

On the other hand, the cyclic voltammograms of trienand Metrien-based complexes (3-6) show one anodic wave and the corresponding cathodic wave, with the exception of solutions of naphthaldehyde derivatives in $\mathrm{MeOH}$, which are irreversibly oxidised (Figure 1). The $E_{1 / 2}$ values for complexes with naphthaldehyde derivatives are less positive than those of the corresponding chlorosalicylaldehyde derivatives. The anodic-cathodic peak potential separations in all solvents are similar to, or (in the case of chlorosalicylaldehyde derivatives) somewhat larger than, those observed for the $\mathrm{Fc}^{+} / \mathrm{Fc}$ couple. The $i_{\mathrm{pc}} / i_{\mathrm{pa}}$ ratios in DMF and $\left(\mathrm{CH}_{3}\right)_{2} \mathrm{SO}$ are practically constant and equal to 1 for the naphthaldehyde derivatives, whereas for the chlorosalicylaldehyde derivatives the ratios are smaller (ca. 0.80). With increasing scan rates, a linear dependence is observed between $i_{\mathrm{p}}$ and $v^{1 / 2}$.

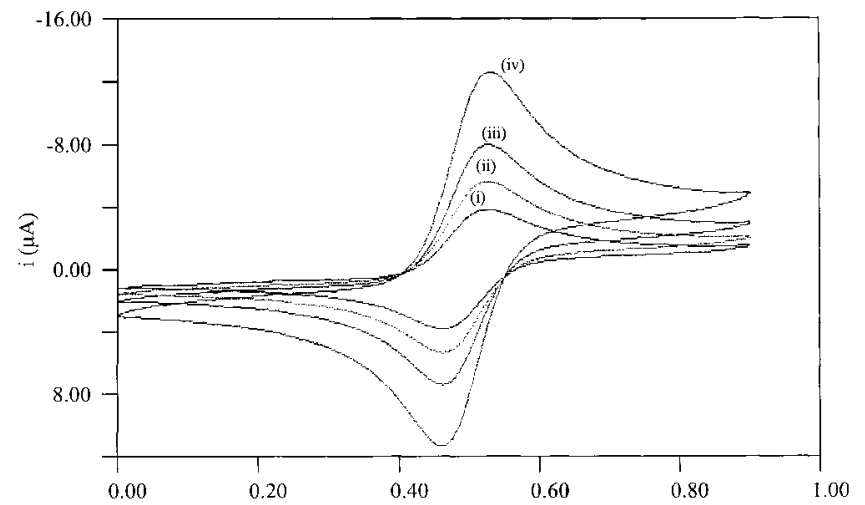

Figure 1. Cyclic voltammograms of [Ni(napMetrien)] (5) in DMF at: (i) 0.05 ; (ii) 0.10 ; (iii) 0.20 , and (iv) $0.50 \mathrm{~V} \cdot \mathrm{s}^{-1}$

Electrochemical data for the complexes with trien and Metrien bridges are consistent with one electron diffusion controlled oxidation process $\mathrm{Ni}^{{ }^{I I}} \rightarrow \mathrm{Ni}^{\mathrm{III}}{ }^{[18]}$ (see below). For complexes with 3,5-dichlorosalicylaldehyde-based ligands $(\mathbf{4}, \mathbf{6})$, there is direct evidence of a chemical decomposition path for the electrogenerated $\mathrm{Ni}^{\mathrm{III}}$ species after charge transfer, whereas for naphthaldehyde derivatives, the decomposition path is not evidenced under the experi- mental conditions used for the cyclic voltammetry. However, during the electrolysis of the complexes (a longer timescale technique), decomposition of the oxidised species was observed for all complexes. Chemical decomposition of electrogenerated $\mathrm{Ni}^{\mathrm{III}}$ species has also been observed in complexes with $\mathrm{N}_{2} \mathrm{O}_{2}$ tetradentate Schiff base ligands, ${ }^{[2,3,11]}$ and although no quantitative studies have been performed for the complexes used in this work, we would like to point out that decomposition of the oxidised species are slower for complexes with pentadentate ligands as compared to $\mathrm{Ni}^{\mathrm{III}}$ species with tetradentate $\mathrm{N}_{2} \mathrm{O}_{2}$ Schiff bases.

Redox Potentials

Our studies on the electrochemical properties of nickel(II) complexes with $\mathrm{N}_{2} \mathrm{O}_{2}$ coordination spheres ${ }^{[1-6]}$ have shown that oxidation of the metal centre is markedly dependent on the donor capacity of the solvent, and is restricted to solvents with good donor properties, such as DMF and $\left(\mathrm{CH}_{3}\right)_{2} \mathrm{SO}$. When an axial nitrogen donor atom capable of binding to the metal centre is introduced into the ligand (as in trien and Metrien) we observe: (i) a stabilisation of the $\mathrm{Ni}^{\mathrm{III}}$ species, as inferred from their lower $E_{1 / 2}$ values and slower decomposition relative to similar $\mathrm{N}_{2} \mathrm{O}_{2}$ nickel(II) complexes, and (ii) a less marked dependence on the solvent. However, in $\mathrm{MeOH}$, a solvent with lower DN value, a reversible process could only be observed for chlorosalicylaldehyde derivatives (stronger ligands). Our results suggest that, even for these five-coordinate ligands, the oxidation requires a moderately strong solvent, which means that axial interactions with solvent molecules still play an important role in the stabilisation of the +3 oxidation state.

As regards the dependence of redox potential on the ligands for complexes 3-6, those with Metrien bridges exhibit more positive $E_{1 / 2}$ values than those with trien bridges, contrary to prediction based upon the relative inductive effects of hydrogen atoms and methyl groups. Similar behaviour has been observed in other nickel complexes with similar trien- and Metrien-based ligands and has been attributed to a weakening of the axial bond due to steric constraints between the methyl groups and the propylene backbone of the bridge. ${ }^{[19,20]}$ On the other hand, the complexes with ligands derived from naphthaldehyde exhibit 
less positive $E_{1 / 2}$ values than those derived from chlorosalicylaldehyde, for which the strongly electron-withdrawing substituents $(\mathrm{Cl})$ should reduce electron density on the chelate ring, and thus on the metal ion, making it harder to oxidise the metal centre.

\section{EPR and Electronic Spectra of the Oxidised Species}

When nickel(II) complexes 3-6 are oxidised electrochemically in DMF, the solution colour changes from greenish to yellow-brown, implying formation of new species. Frozenmatrix EPR spectra of all electrolysed solutions are similar, and show significant rhombicity and large $g$ tensor anisotropy, with $g_{\mathrm{av}}\left[g_{\mathrm{av}}=\left(g_{1}+g_{2}+g_{3}\right) / 3\right]$ in the range $2.13-2.15\left(g_{1} \approx 2.24-2.26, g_{2} \approx 2.13-2.16\right.$ and $g_{3} \approx$ 2.02-2.04): an indication that the oxidised species must correspond to nickel(III) complexes. Furthermore, all spectra show a well resolved 1:1:1 triplet in the high magnetic field region, with $a \approx 1.80-2.17 \mathrm{mT}$. EPR spectra of nickel(III) species with naptrien and napMetrien in DMF are presented in Figure 2 (A) and Figure 3 (A), respectively; EPR data for the electrogenerated nickel(III) species in DMF are summarised in Table 2.
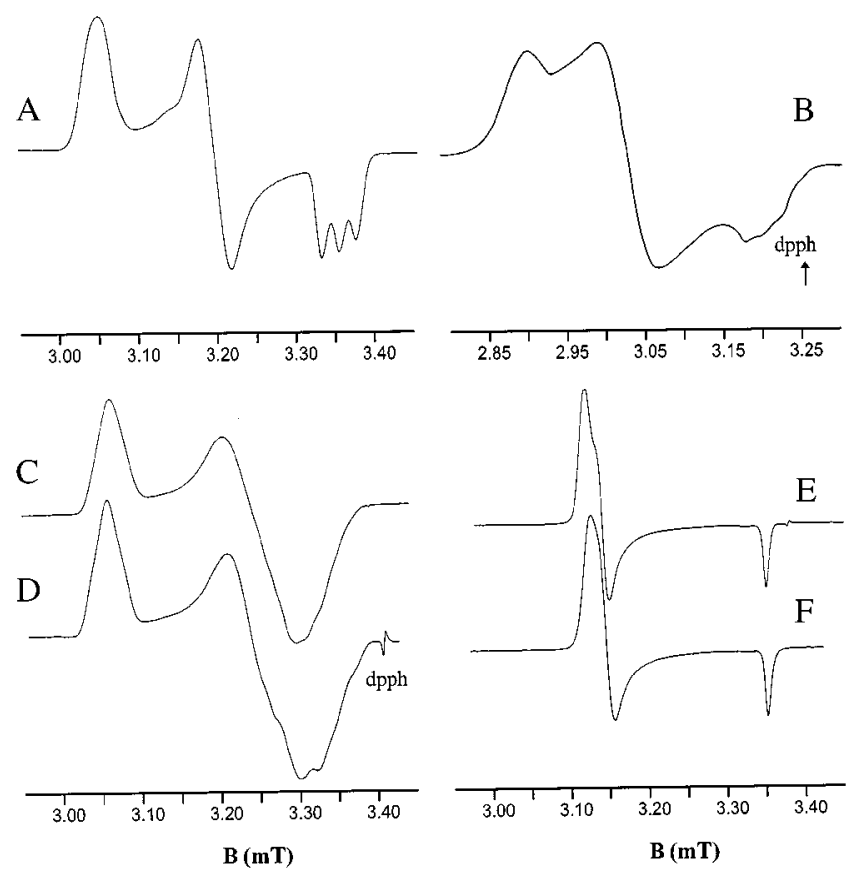

Figure 2. Frozen EPR spectra of $\left[\mathrm{Ni}^{\mathrm{III}} \text { (naptrien) }\right]^{+}$in: (A) DMF; (B) $\mathrm{CH}_{3} \mathrm{CN}$; (C) pyridine; (D) $\left[{ }^{15} \mathrm{~N}\right]$ pyridine; (E) $\mathrm{CN}^{-}$, and (F) ${ }^{13} \mathrm{CN}^{-}$

Chemical oxidation of complexes 3-6 with iodine were first performed in DMF. Frozen-matrix EPR spectra of these solutions are identical to those of electrolysed solutions and thus imply the same coordination environment for the nickel(III) species, regardless of the oxidation method used. We also observed that chemically oxidised solutions, owing to the presence in solution of excess oxidant, are more stable at room temperature than those obtained electrochemically.
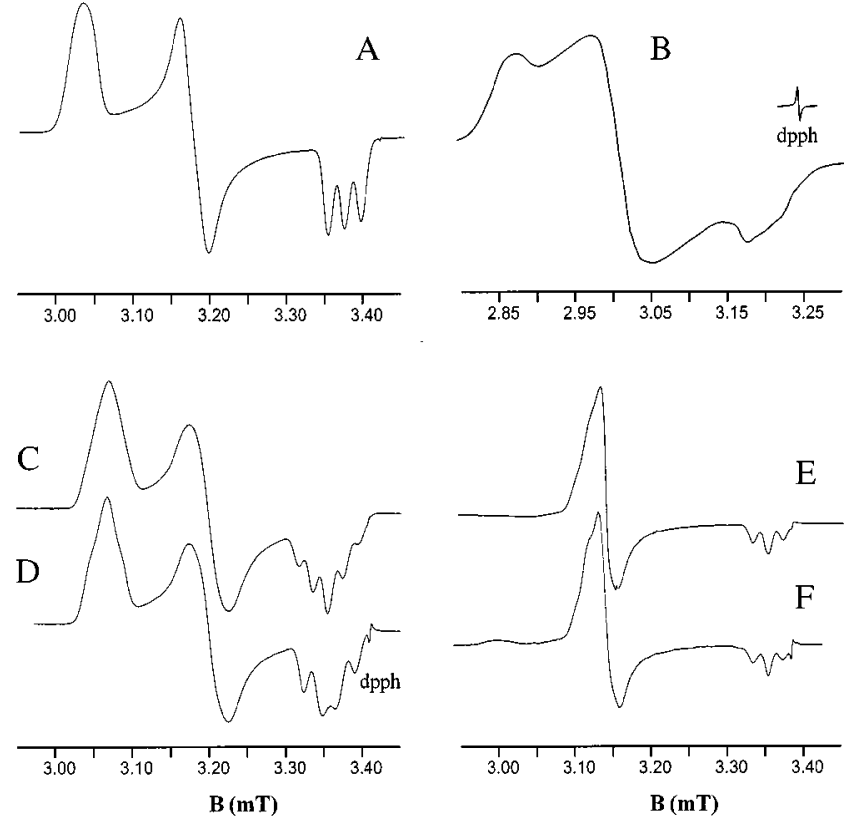

Figure 3. Frozen EPR spectra of $\left[\mathrm{Ni}^{\mathrm{III}}(\text { napMetrien) }]^{+}\right.$in: (A) DMF; (B) $\mathrm{CH}_{3} \mathrm{CN}$; (C) $\left[{ }^{15} \mathrm{~N}\right]$ pyridine; (D) pyridine; (E) $\mathrm{CN}^{-}$, and $(\mathrm{F}){ }^{13} \mathrm{CN}^{-}$

The similarity of the EPR and the longer half-lives of the chemically oxidised solutions, prompted us to examine chemical oxidation of complexes 1-6 (hence including complexes with dien bridges) in other solvents. The study was extended to two other O-donor solvents, $\mathrm{MeOH}$, and $\left(\mathrm{CH}_{3}\right)_{2} \mathrm{SO}$, and to acetonitrile, a N-donor solvent.

Chemically oxidised solutions of complexes 3-6 in $\mathrm{MeOH}$ and $\left(\mathrm{CH}_{3}\right)_{2} \mathrm{SO}$ exhibit frozen EPR spectra that are very similar to those in DMF, with $g$ values in the same range, and a well resolved triplet $(1: 1: 1)$ observed in the high magnetic field region, with $a_{3}=2.03-2.30 \mathrm{mT}$. Frozen EPR spectra of the chemically oxidised solutions in $\mathrm{MeCN}$ exhibit the same $g$ features as those in the O-donor solvents, but with a poorly resolved multiplet, not a triplet, in the high magnetic field region. The spectra for nickel(III) species with trien- and Metrien-based ligands in $\mathrm{MeCN}$ are presented in Figure 2(B) and 3(B), and the EPR parameters are summarised in Table 2.

Solutions of $[\mathrm{Ni}$ (napdien) $)$ and $\left[\mathrm{Ni}\left(\mathrm{Cl}_{4}\right.\right.$ saldien $\left.)\right](\mathbf{1}, \mathbf{2})$ were also chemically oxidised in the same solvents, and the oxidised samples were immediately frozen in liquid nitrogen. The oxidised solutions exhibit EPR spectra, but their $g$ features depend on the solvent used. EPR data for 1-2 are presented in Table 2 and spectra of $\mathbf{1}$ are depicted in Figure 4. In DMF and $\left(\mathrm{CH}_{3}\right)_{2} \mathrm{SO}$, the spectra exhibit large $g$ tensor anisotropy, with $g_{\text {av }}$ in the range 2.15-2.16, and small rhombicity; however, no hyperfine couplings were detected in any $g$ region (Figure 4, C,D). The EPR spectrum in $\mathrm{MeCN}$ shows two superimposed signals with similar intensities: one signal for which the low-field components have a $g$ value similar to those of the chemically oxidised species in DMF and $\left(\mathrm{CH}_{3}\right)_{2} \mathrm{SO}$, and one isotropic signal, with $g \approx 2.00$, due to radical species, which masks the highfield component of the other signal (Figure 4, B); in $\mathrm{MeOH}$ 
Table 2. EPR parameters for nickel(III) species in several solvents

\begin{tabular}{|c|c|c|c|c|c|c|c|c|c|c|c|}
\hline Complex & Solvent & $g_{x}$ & $g_{y}$ & $g_{z}$ & $g_{\mathrm{av}}^{[\mathrm{a}]}$ & $a(\mathrm{~N})_{x}^{1[\mathrm{~b}]}$ & $a(\mathrm{~N})_{y}^{1[\mathrm{~b}]}$ & $a(\mathrm{~N})_{z}^{1[\mathrm{~b}]}$ & $a(\mathrm{~N})_{x}^{2[\mathrm{~b}]}$ & $a(\mathrm{~N})_{y}^{2[\mathrm{~b}]}$ & $a(\mathrm{~N})_{z}^{2[\mathrm{~b}]}$ \\
\hline \multirow{4}{*}{$\begin{array}{c}\left.\mathrm{Ni}\left(\mathrm{Cl}_{4} \text { saltrien }\right)\right]^{+} \\
(\mathbf{4})\end{array}$} & $\mathrm{CH}_{3} \mathrm{OH}$ & 2.236 & 2.139 & 2.038 & 2.138 & 1.30 & 1.60 & 2.05 & \multirow{4}{*}{0.80} & \multirow{4}{*}{0.80} & \multirow{4}{*}{1.30} \\
\hline & $\mathrm{CH}_{3} \mathrm{CN}$ & 2.231 & 2.140 & 2.044 & 2.138 & 16.00 & 1.80 & 2.05 & & & \\
\hline & DMF & 2.236 & 2.132 & 2.039 & 2.136 & 1.30 & 1.70 & 2.10 & & & \\
\hline & $\left(\mathrm{CH}_{3}\right)_{2} \mathrm{SO}$ & 2.236 & 2.130 & 2.040 & 2.135 & 15.00 & 1.80 & 2.05 & & & \\
\hline \multirow{4}{*}{ 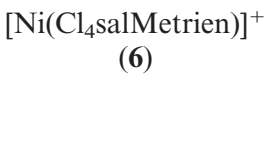 } & $\mathrm{CH}_{3} \mathrm{OH}$ & 2.248 & 2.154 & 2.034 & 2.145 & 1.30 & 1.50 & 2.20 & \multirow{4}{*}{0.80} & \multirow{4}{*}{0.80} & \multirow{4}{*}{1.35} \\
\hline & $\mathrm{CH}_{3} \mathrm{CN}$ & 2.240 & 2.153 & 2.041 & 2.145 & 1.40 & 1.80 & 2.10 & & & \\
\hline & DMF & 2.247 & 2.154 & 2.033 & 2.145 & 1.30 & 16.00 & 2.15 & & & \\
\hline & $\left(\mathrm{CH}_{3}\right)_{2} \mathrm{SO}$ & 2.248 & 2.154 & 2.035 & 2.146 & 1.30 & 16.00 & 2.20 & & & \\
\hline \multirow{4}{*}{${ }_{(\mathbf{3})}^{[\mathrm{Ni}(\text { naptrien })]^{+}}$} & $\mathrm{CH}_{3} \mathrm{OH}$ & 2.250 & 2.156 & 2.032 & 2.146 & 1.60 & 1.80 & 2.26 & \multirow{4}{*}{0.80} & \multirow{4}{*}{0.80} & \multirow{4}{*}{1.30} \\
\hline & $\mathrm{CH}_{3} \mathrm{CN}$ & 2.235 & 2.145 & 2.040 & 2.140 & 1.60 & 1.80 & 2.30 & & & \\
\hline & DMF & 2.237 & 2.143 & 2.033 & 2.138 & 1.60 & 1.80 & 2.30 & & & \\
\hline & $\left(\mathrm{CH}_{3}\right)_{2} \mathrm{SO}$ & 2.237 & 2.139 & 2.034 & 2.137 & 1.70 & 19.70 & 2.35 & & & \\
\hline \multirow{4}{*}{$\begin{array}{c}{[\mathrm{Ni}(\text { napMetrien })]^{+}} \\
(\mathbf{5})\end{array}$} & $\mathrm{CH}_{3} \mathrm{OH}$ & 2.240 & 2.144 & 2.032 & 2.139 & 1.90 & 2.10 & 2.40 & \multirow{4}{*}{0.80} & \multirow{4}{*}{0.80} & \multirow{4}{*}{1.30} \\
\hline & $\mathrm{CH}_{3} \mathrm{CN}$ & 2.250 & 2.156 & 2.038 & 2.148 & 1.60 & 1.80 & 2.20 & & & \\
\hline & DMF & 2.255 & 2.153 & 2.030 & 2.146 & 1.50 & 1.80 & 2.20 & & & \\
\hline & $\left(\mathrm{CH}_{3}\right)_{2} \mathrm{SO}$ & 2.252 & 2.155 & 2.032 & 2.146 & 1.50 & 1.95 & 2.28 & & & \\
\hline \multirow{4}{*}{$\underset{(2)}{\left[\mathrm{Ni}_{\left(\mathrm{Cl}_{4} \text { saldien }\right)}\right]^{+}}$} & $\mathrm{CH}_{3} \mathrm{OH}$ & [c] & & & & & & & & & \\
\hline & $\mathrm{CH}_{3} \mathrm{CN}$ & [d] & & & & & & & & & \\
\hline & DMF & 2.230 & 2.200 & 2.018 & 2.149 & & & & & & \\
\hline & $\left(\mathrm{CH}_{3}\right)_{2} \mathrm{SO}$ & 2.220 & 2.202 & 2.022 & 2.148 & & & & & & \\
\hline \multirow{4}{*}{${ }_{\text {(1) }}^{[\mathrm{Ni}(\text { napdien })]^{+}}$} & $\mathrm{CH}_{3} \mathrm{OH}$ & [c]) & & & & & & & & & \\
\hline & $\mathrm{CH}_{3} \mathrm{CN}$ & [d]) & & & & & & & & & \\
\hline & DMF & 2.240 & 2.210 & 2.025 & 2.158 & & & & & & \\
\hline & $\left(\mathrm{CH}_{3}\right)_{2} \mathrm{SO}$ & 2.230 & 2.202 & 2.021 & 2.151 & & & & & & \\
\hline
\end{tabular}

[a] The value of $g_{\text {av }}$ was calculated as $\left(\mathrm{g}_{x}+\mathrm{g}_{y}+\mathrm{g}_{z}\right) / 3 . \quad-{ }^{[\mathrm{b}]} a(\mathrm{~N})$ values are expressed in $\mathrm{mT}$. - [c] EPR spectrum typical of a radical species with $g=2.003$. $-{ }^{[\mathrm{d}]}$ Two superimposed EPR spectra are observed: typical of $\mathrm{Ni}^{\mathrm{III}}$ and radical species.

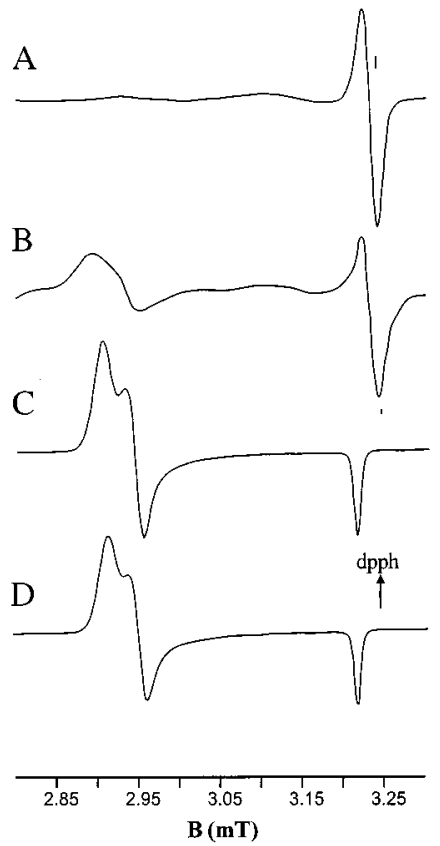

Figure 4. Frozen EPR spectra of $\left[\mathrm{Ni}^{\mathrm{III}}(\text { napdien) }]^{+}\right.$in: (A) $\mathrm{CH}_{3} \mathrm{OH}$; (B) $\mathrm{CH}_{3} \mathrm{CN}$; (C) DMF, and (D) $\left(\mathrm{CH}_{3}\right)_{2} \mathrm{SO}$

the spectrum exhibits only the isotropic signal at $g \approx 2.00$ (Figure 4, A).

The similarity between the $g$ values in the spectra of the chemically oxidised $\left[\mathrm{Ni}\left(\mathrm{Cl}_{4}\right.\right.$ saldien $\left.)\right]$ and $[\mathrm{Ni}($ napdien $)]$ and in those of low-spin, six-coordinate nickel(III) with $\mathrm{N}_{2} \mathrm{O}_{2}$ related Schiff ligands may be used as a basis for proposing that complexes $\mathbf{1 - 2}$ have the same ${ }^{2} \mathrm{~A}_{1}$ ground state, $\left[a \mathrm{~d}_{z}{ }^{2}\right.$ $\left.+b \mathrm{~d}_{x^{2}-y^{2}}\right]$, with $a>>b: C_{2 \mathrm{v}}(z) \cdot{ }^{[1-6,21-25]}$ Thus, the lack of observed hyperfine coupling with any nitrogen atom in the EPR spectra indicates that the amine nitrogen atom remains unbound; hence the ligand behaves as a tetradentate $\mathrm{N}_{2} \mathrm{O}_{2}$ donor towards $\mathrm{Ni}^{\mathrm{III}}$. The transient nickel(III) species are low-spin and six-coordinate, with two solvent molecules (Solv) axially bound, and can be formulated as $\left[\mathrm{Ni}^{\mathrm{III}} \mathrm{L}(\mathrm{Solv})_{2}\right]^{+}$, with $\mathrm{L}=$ napdien or $\mathrm{Cl}_{4}$ saldien (Scheme 2).

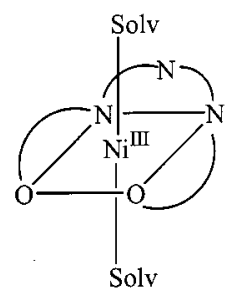

$\left[\mathrm{Ni}^{\mathrm{III}}(\mathrm{L})(\mathrm{Solv})_{2}\right]^{+}$

$\mathrm{L}=$ napdien, $3,5-\mathrm{Cl}_{4}$ saldien

Solv $=\mathrm{dmf},\left(\mathrm{CH}_{3}\right)_{2} \mathrm{SO}$

Scheme 2

In $\mathrm{MeCN}$, two EPR signals were observed: one of radical-type and another from one metal-centred oxidised species. The radical species may be short-lived intermediates in the chemical decomposition path of the oxidised $\mathrm{Ni}^{\mathrm{III}}$ complexes. No analysis of the nickel(III) species can be performed, as the intense signal at $g=2.00$ masks the high- 
field component, but the similarity of the low-field components with those of nickel(III) species in DMF and $\left(\mathrm{CH}_{3}\right)_{2} \mathrm{SO}$ implies the formation of $\left[\mathrm{Ni}^{\mathrm{iII}} \mathrm{L}(\mathrm{MeCN})_{2}\right]^{+}$in solution. In $\mathrm{MeOH}$ only the signal assigned to radical species was observed, but this signal cannot be assigned unambiguously, since two possible explanations can be invoked: it may (i) be due to short-lived intermediates in the chemical decomposition of putative $\mathrm{Ni}^{\mathrm{III}}$ oxidised species, or (ii) be the end result of direct oxidation on the ligand.

In contrast, nickel(II) complexes 3-6 are oxidised to $\mathrm{Ni}^{\mathrm{III}}$ species in all solvents used, and their EPR spectra show behaviour quite different from that of the related complexes with dien-based bridges (Figure 2, Figure 3, and Figure 4). The EPR spectra are more rhombic, but as the difference $g_{1}-g_{2}$ is still smaller than $g_{2}-g_{3}$, the ground state must also be ${ }^{2} \mathrm{~A}_{1},\left[a \mathrm{~d}_{z^{2}}+b \mathrm{~d}_{x^{2}-y^{2}}\right]$, although with $a$ $\geq b$, and thus $g_{1}=g_{x}, g_{2}=g_{y}$, and $g_{3}=g_{z} \cdot{ }^{[21-24]}$ The observation of one well-resolved triplet in the low $g$ region $\left(g_{\mathrm{z}}\right)$ in O-donor solvents, changing to a poorly resolved multiplet in $\mathrm{MeCN}$, is indicative that: (i) the polydentate ligands act in pentadentate fashion, with the amine nitrogen atom axially bound as in the parent $\mathrm{Ni}^{\mathrm{II}}$ complex, and (ii) the sixth coordination site is occupied by a solvent molecule. The $\mathrm{Ni}^{\mathrm{III}}$ complexes are thus formulated as $\left[\mathrm{Ni}^{\mathrm{III}} \mathrm{L}(\mathrm{Solv})\right]^{+}$, with $\mathrm{L}$ denoting pentadentate trien- or Metrien-based ligands (Scheme 3 and Scheme 4).

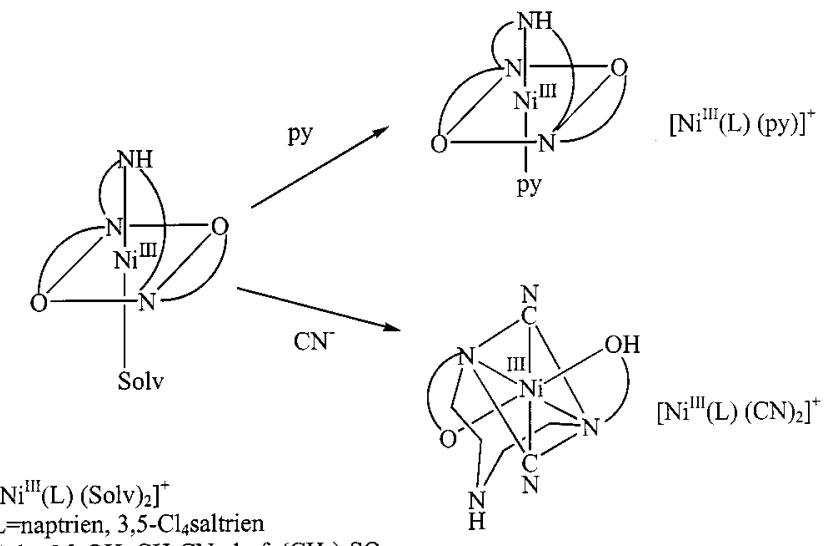

Solv $=\mathrm{MeOH}, \mathrm{CH}_{3} \mathrm{CN}$, dmf, $\left(\mathrm{CH}_{3}\right)_{2} \mathrm{SO}$

Scheme 3

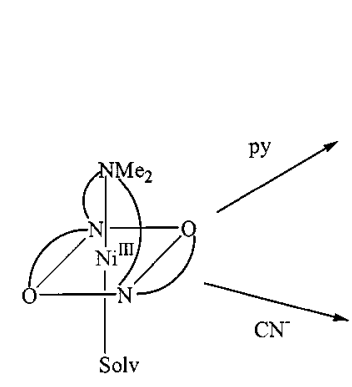

$\left[\mathrm{Ni}^{\mathrm{III}}(\mathrm{L})(\mathrm{Solv})_{2}\right]^{+}$

$\mathrm{L}=$ napMetrien, $3,5-\mathrm{Cl}_{4}$ salMetrien

Solv $=\mathrm{MeOH}, \mathrm{CH}_{3} \mathrm{CN}, \mathrm{dmf},\left(\mathrm{CH}_{3}\right)_{2} \mathrm{SO}$

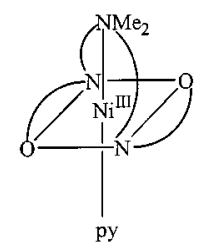

$\left[\mathrm{Ni}^{\mathrm{III}}(\mathrm{L})(\mathrm{py})\right]^{+}$
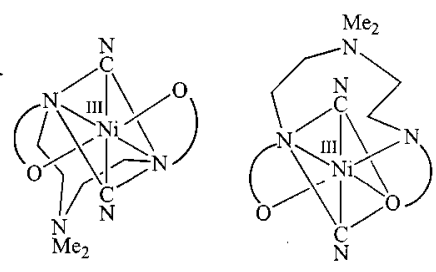

$\left[\mathrm{Ni}^{1111}(\mathrm{~L})(\mathrm{CN})_{2}\right]^{+}$
Electronic spectra of electrochemically and chemically oxidised solutions of complexes 3-6 in DMF are very similar in the NIR region, but the very intense bands due to the iodine/iodide pair in the chemically oxidised solutions prevent comparisons below $\lambda=600 \mathrm{~nm}$. No electronic spectra could be obtained for electrochemically or chemically oxidised solutions of complexes $\mathbf{1 - 2}$ in DMF, since decomposition of oxidised species is very fast even in cold fluid solutions (just above the melting point).

Electronic spectra of electrochemically oxidised solutions of 3-6 in DMF exhibit a very broad, medium intensity band in the near IR region $\left(\lambda_{\max }=950-1100 \mathrm{~nm}, \varepsilon=\right.$ $\left.200-900 \mathrm{~mol}^{-1} \mathrm{dm}^{3} \mathrm{~cm}^{-1}\right)$ and very intense bands at $\lambda_{\max }$ $<550 \mathrm{~nm}\left(\varepsilon>3000 \mathrm{~mol}^{-1} \mathrm{dm}^{3} \mathrm{~cm}^{-1}\right)$. Spectra recorded sequentially at 5 -min intervals reveal (i) a gradual weakening in the NIR band, until it disappears completely, and (ii) a simultaneous blue shift of the high intensity bands. The spectra obtained after the disappearance of the NIR band are typical of nickel(II) complexes and correspond to solutions in which all nickel(III) species have decomposed, as confirmed by their silent EPR spectra. Moreover, since no electronic bands due to nickel(II) precursors could be detected above $400 \mathrm{~nm}$, the medium intensity NIR bands in the spectra of oxidised solutions may thus be unambiguously attributed to d-d transitions of nickel(III) species generated in situ. The high-intensity bands include chargetransfer bands attributed to $\mathrm{Ni}^{\mathrm{III}}$ species and to $\mathrm{Ni}^{\mathrm{II}}$ precursor complexes/nickel(II) decomposed species. Electronic spectral data for nickel(III) species are presented in Table 3.

Table 3. Electronic spectral data for $\mathrm{Ni}^{\mathrm{III}}$ complexes in DMF and in the presence of Lewis bases

\begin{tabular}{|c|c|c|}
\hline Complex & Co-ligand & $\lambda_{\max }(\mathrm{nm}) / \varepsilon\left(\mathrm{mmol}^{-1} \mathrm{dm}^{3} \mathrm{~cm}^{-1}\right)^{[\mathrm{a}]}$ \\
\hline$\left[\underset{(\mathbf{6})}{\left[\mathrm{Ni}\left(\mathrm{Cl}_{4} \mathrm{salMetrien}\right)\right]^{+}}\right.$ & $\begin{array}{l}\mathrm{DMF} \\
\text { pyridine } \\
\mathrm{CN}^{-}\end{array}$ & $\begin{array}{c}995 \text { br }(1.3) ;<500 \\
1000 \text { br }(0.46) ;<500 \\
<500\end{array}$ \\
\hline$\left[\underset{(5)}{[\mathrm{Ni}(\text { napMetrien })]^{+}}\right.$ & $\begin{array}{l}\mathrm{DMF} \\
\text { pyridine } \\
\mathrm{CN}^{-}\end{array}$ & $\begin{array}{c}1082 \text { br }(0.61) ;<500 \\
975 \text { br }(0.77) ;<500 \\
793 \text { br }(0.58) ;<500\end{array}$ \\
\hline$\underset{(\mathbf{4})}{\left[\mathrm{Ni}^{\left(\mathrm{Cl}_{4} \text { saltrien }\right)}\right]^{+}}$ & $\begin{array}{l}\text { DMF } \\
\text { pyridine } \\
\mathrm{CN}^{-}\end{array}$ & $\begin{array}{c}971 \text { br }(0.91) ;<500 \\
975 \text { br }(0.28) ;<500 \\
<<500\end{array}$ \\
\hline${ }_{(\mathbf{3})}^{[\mathrm{Ni}(\text { naptrien })]^{+}}$ & $\begin{array}{l}\mathrm{DMF} \\
\text { pyridine } \\
\mathrm{CN}^{-}\end{array}$ & $\begin{array}{c}1043 \text { br }(1.2) ;<500 \\
980 \text { br }(1.1) ;<500 \\
700 \text { br }(0.37) ;<500\end{array}$ \\
\hline
\end{tabular}

[a] $\varepsilon$ values were estimated assuming that all complexes had been quantitatively oxidised to $\mathrm{Ni}^{\mathrm{III}}$ and that no decomposition of the oxidised species had taken place.

Electronic band maxima occur in the range of values observed for six-coordinate nickel(III) complexes with $\mathrm{N}_{2} \mathrm{O}_{2}$ Schiff base ligands derived from the same aldehyde derivatives and two solvent molecules. ${ }^{[2-6]}$ Analysis of the data in Table 3 reveals that the general trends in band maxima observed for the precursor $\mathrm{Ni}^{\mathrm{II}}$ complexes also apply to the corresponding nickel(III) species: (i) complexes with dichlo-

Scheme 4 
rosalicylaldehyde derivatives have electronic bands at shorter wavelengths than those with naphthaldehyde, hence suggesting that the latter ligands also act as weaker ligands for nickel(III), and (ii) given the same aldehyde moiety, complexes with Metrien bridges have band maxima at longer wavelengths than those with trien bridges, indicating that the methyl group, due to steric constraints as outlined for the parent nickel(II) complexes, does not increase the ligand field.

\section{Pyridine Adducts}

The solutions obtained by addition of pyridine, and of cyanide ions, to $\left[\mathrm{Ni}^{\mathrm{III}} \mathrm{L}(\mathrm{Solv})_{2}\right]^{+}, \mathrm{L}=$ napdien and $\mathrm{Cl}_{4}$ saldien $(\mathbf{1}, \mathbf{2})$ were found to be EPR-silent, which suggests that the decomposition rate of the new species must be fast enough to prevent observation with the experimental setup used.

Upon addition of pyridine (natural abundance and ${ }^{15} \mathrm{~N}$ enriched) to freshly prepared DMF solutions of $\left[\mathrm{Ni}^{\mathrm{III}} \mathrm{L}(\mathrm{DMF})\right]^{+}\left(\mathrm{L}=\right.$ naptrien, napMetrien, $\mathrm{Cl}_{4}$ saltrien, $\mathrm{Cl}_{4}$ salMetrien), new species were formed, as could be inferred from the rapid colour change to dark brown. The resulting solutions are EPR-active and the frozen solution spectra of complexes with trien and Metrien bridges exhibit different $g$ patterns.

\section{Complexes with Metrien Bridge Ligands}

The EPR spectra of $\left[{ }^{14} \mathrm{~N}\right]$ py adducts with $\left[\mathrm{Ni}^{\mathrm{III}} \mathrm{L}(\mathrm{DMF})\right]^{+}\left(\mathrm{L}=\right.$ napMetrien, $\mathrm{Cl}_{4}$ salMetrien $)$, are similar, with rhombic symmetry and a $g$ pattern $\left(g_{1}-g_{2} \leq g_{2}\right.$ $-g_{3}$ ) that resembles that of the nickel(III) precursor complexes. In the high magnetic field region, a well-resolved quintuplet is observed (Figure 3, C), with an apparent 1:2:3:2:1 intensity pattern with $a_{3}=0.19 \mathrm{mT}$. The ground state is thus assumed to be ${ }^{2} \mathrm{~A}_{1},\left[a \mathrm{~d}_{z^{2}}+b \mathrm{~d}_{x^{2}-y^{2}}\right]$, with $a \geq$ $b$, and $g_{1}=g_{x}, g_{2}=g_{y}$, and $g_{3}=g_{z} \cdot{ }^{[21-25]}$

The need to identify the origin of the quintuplet prompted us to perform the same experiments, but using $\left[{ }^{15} \mathrm{~N}\right]$ py $\left({ }^{15} \mathrm{~N} ; I=1 / 2\right)$. The multiplet in the high magnetic field region became a quadruplet $(1: 2: 2: 1)$, arising from the interaction of the unpaired electron with two nitrogen atoms with different $I$ values [the amine nitrogen atom $\left(\mathrm{N}_{\text {amine }} ; I=1\right)$ and the pyridine nitrogen atom $\left(\mathrm{N}_{\mathrm{py}}\right.$; $I=1 / 2)]$, but with similar hyperfine couplings $\left[a_{\mathrm{N}(\mathrm{amine})}=\right.$ $1.20 ; 1.50$, and $2.10 \mathrm{mT}$ and $a_{\mathrm{N}(\mathrm{py})}=0.80 ; 0.10$, and $2.10 \mathrm{mT}]$. In this context, the quintuplet observed in the $\left[{ }^{14} \mathrm{~N}\right]$ py adducts arises from coupling to two different nitrogen atoms - one from the pentadentate ligand and the other from pyridine - but with similar coupling constants (Table 4). The complexes are thus formulated as low-spin, six-coordinate complexes, $\left[\mathrm{Ni}^{\mathrm{III}}(\mathrm{L})(\mathrm{py})\right]^{+}$, in which the ligand $\mathrm{L}\left(\mathrm{L}=\right.$ napMetrien or $\mathrm{Cl}_{4}$ salMetrien $)$ acts in pentadentate fashion, and one pyridine molecule is bound at the sixth position (Scheme 4).

\section{Complexes with trien Bridge Ligands}

The EPR spectra of $\left[{ }^{14} \mathrm{~N}\right]$ py adducts with $\left[\mathrm{Ni}^{\mathrm{III}} \mathrm{L}(\mathrm{DMF})\right]^{+}$when $\mathrm{L}=$ naptrien and $\mathrm{Cl}_{4}$ saltrien are dif- ferent from those with Metrien bridges. They exhibit apparent axial symmetry with large $g$ tensor anisotropy, and with a weakly resolved quintuplet $\left(a_{3} \approx 0.17-0.20 \mathrm{mT}\right)$ in the high magnetic field region, but with a $g$ pattern different to those of the nickel(III) precursor complexes and of the homologous Metrien-based compounds. The $g$ pattern is now $g_{1}-g_{2}>g_{2}-g_{3}$, with $g_{1} \approx 2.21, g_{2} \approx 2.09$ and $g_{3} \approx$ 2.06 (Table 4). These spectra are consistent with the presence in solution of axially compressed six-coordinate species with a ground state that is essentially $\mathrm{d}_{\mathrm{x}-\mathrm{y}}{ }^{2}\left({ }^{2} \mathrm{~A}_{1},[a\right.$ $\mathrm{d}_{z}{ }^{2}+b$ ], with $\left.a<<b\right)$, and in this case $g_{1}=g_{z}, g_{2}=g_{x}$, and $g_{3}=g_{y}{ }^{[21-25]}$ Furthermore, the adducts with $\left[{ }^{15} \mathrm{~N}\right] \mathrm{py}$ exhibit EPR spectra that are identical to those with $\left[{ }^{14} \mathrm{~N}\right] \mathrm{py}$, which implies that the hyperfine splittings cannot be due to coordinate pyridine molecules but must arise from the equatorial plane imine nitrogen atoms of the pentadentate ligand, in accordance with the ground state assignment.

Electronic data for the pyridine adducts are summarised in Table 3. The spectra show a broad, medium-intensity band in the NIR region, $\lambda=975-1000 \mathrm{~nm}$, and high-intensity bands below $450 \mathrm{~nm}$. On monitoring the spectra at 5-min intervals it was possible to observe a continuous loss of band absorbance for the electronic transition at low energies and a blue shift of the intense bands at high energies, an unambiguous indication that the bands in the NIR are due to $\mathrm{d}-\mathrm{d}$ transitions in $\mathrm{Ni}^{\mathrm{III}}$ pyridine adducts. The $\mathrm{d}-\mathrm{d}$ bands are shifted to higher energies relative to those of the $\mathrm{Ni}^{\mathrm{III}}$ precursor species, and the shift is related to the increase in ligand field when the sixth axial ligand is changed from DMF to pyridine.

Although no direct information concerning the number of coordinated pyridine molecules could be obtained, we propose that, in the adducts with naptrien and $\mathrm{Cl}_{4}$ saltrien, only one pyridine should be bound (Scheme 3), since in complexes with Metrien base ligands, which impose weaker ligand fields, only one pyridine molecule is bound to the nickel centre.

\section{Cyanide Adducts}

Upon addition of potassium cyanide, the solution colour of freshly electrooxidised solutions of $\left[\mathrm{Ni}^{\mathrm{III}} \mathrm{L}(\mathrm{DMF})\right]^{+}$ (with $\mathrm{L}=$ naptrien, napMetrien, $\mathrm{Cl}_{4}$ saltrien, $\mathrm{Cl}_{4}$ salMetrien) changes from yellow-brown to green. Frozen solutions of cyanide adducts show EPR spectra that are typical of $\mathrm{Ni}^{\mathrm{iII}}$ species, but with a $g$ pattern different to that observed for the parent $\mathrm{Ni}^{\mathrm{iII}}$ complexes and to those of pyridine adducts. These observations provide a clear indication that cyanide binds to the nickel(III) centres.

Frozen-matrix EPR spectra of all cyanide adducts show quasi-axial symmetry and a $g$ pattern typical of low-spin, six-coordinate complexes with axial elongation, and with a ${ }^{2} \mathrm{~A}_{1}$ ground state, $\left[a \mathrm{~d}_{z^{2}}+b \mathrm{~d}_{x^{2}-y^{2}}\right]$, with $a>b ; g_{1}=$ $2.18-2.16, g_{2}=2.16-2.15, g_{3} \approx 2.02$, and $g_{1}=g_{x}, g_{2}=g_{y}$ and $g_{3}=g_{z}$ in both cases (Table 4). ${ }^{[1-6,21-25]}$ No hyperfine splittings were detected in the spectra of the adducts with trien-based ligands (Figure 2, E), but those of Metrienbased complexes exhibit a high-field signal split into three lines (not 1:1:1 triplet, $a=0.19 \mathrm{mT}$ ) (Figure 3, E). In order 
Table 4. EPR parameters for nickel(III) species in the presence of pyridine and cyanide ions

\begin{tabular}{|c|c|c|c|c|c|c|c|c|c|c|c|}
\hline Complex & Co-ligand & $g_{x}$ & $g_{y}$ & $g_{z}$ & $g_{\mathrm{av}}^{[\mathrm{a}]}$ & $a(\mathrm{~N})_{x}^{1[\mathrm{~b}]}$ & $a(\mathrm{~N})_{y}^{1[\mathrm{~b}]}$ & $a(\mathrm{~N})_{z}^{1[\mathrm{~b}]}$ & $a(\mathrm{~N})_{x}^{2[\mathrm{~b}]}$ & $a(\mathrm{~N})_{y}^{2[\mathrm{~b}]}$ & $a(\mathrm{~N})_{z}^{2[\mathrm{~b}]}$ \\
\hline \multirow{5}{*}{$\mathrm{Ni}_{(6)} \mathrm{Cl}_{4}$ salMetrien }$]^{+}$ & \multirow{3}{*}{$\begin{array}{c}{\left[{ }^{14} \mathrm{~N}\right] \text { pyridine }} \\
\mathrm{CN}^{-}\end{array}$} & 2.223 & 2.123 & 2.039 & 2.128 & \multirow[t]{2}{*}{1.10} & \multirow[t]{2}{*}{1.30} & \multirow[t]{2}{*}{1.89} & \multirow[t]{5}{*}{1.10} & \multirow[t]{5}{*}{1.30} & \multirow[t]{5}{*}{18.90} \\
\hline & & 2.173 & 2.147 & 2.022 & 2.114 & & & & & & \\
\hline & & 2.178 & 2.163 & 2.022 & 2.121 & \multirow[t]{2}{*}{1.30} & \multirow[t]{2}{*}{1.30} & \multirow[t]{2}{*}{21.00} & & & \\
\hline & \multirow[t]{2}{*}{${ }^{13} \mathrm{CN}^{-}$} & 2.177 & 2.164 & 2.021 & 2.121 & & & & & & \\
\hline & & 2.183 & 2.155 & 2.021 & 2.120 & 1.50 & 1.50 & 20.00 & & & \\
\hline \multirow{7}{*}{$\underset{(5)}{[\mathrm{Ni}(\text { napMetrien })]^{+}}$} & \multirow{4}{*}{$\begin{array}{c}{\left[{ }^{14} \mathrm{~N}\right] \text { pyridine }} \\
{\left[{ }^{15} \mathrm{~N}\right] \text { pyridine }} \\
\mathrm{CN}^{-}\end{array}$} & 2.224 & 2.132 & 2.035 & 2.130 & 1.00 & 12.00 & 19.00 & \multirow{6}{*}{$\begin{array}{l}1.00 \\
0.60\end{array}$} & \multirow{6}{*}{$\begin{array}{l}1.20 \\
1.00\end{array}$} & \multirow{6}{*}{$\begin{array}{l}1.90 \\
2.10\end{array}$} \\
\hline & & 2.225 & 2.133 & 2.034 & 2.131 & 1.20 & 1.50 & 2.10 & & & \\
\hline & & 2.162 & 2.150 & 2.022 & 2.111 & & & & & & \\
\hline & & 2.163 & 2.161 & 2.022 & 2.115 & 1.30 & 1.30 & 2.05 & & & \\
\hline & \multirow[t]{3}{*}{${ }^{13} \mathrm{CN}^{-}$} & 2.161 & 2.156 & 2.022 & 2.113 & & & & & & \\
\hline & & 2.163 & 2.157 & 2.022 & 2.114 & 1.30 & 1.30 & 2.05 & & & \\
\hline & & $g_{\mathrm{z}}$ & $g_{\mathrm{x}}$ & $g_{\mathrm{y}}$ & $g_{\mathrm{av}}[\mathrm{a}]$ & $a(\mathrm{~N})_{\mathrm{z}}^{[\mathrm{b}]}$ & $a(\mathrm{~N})_{\mathrm{x}}^{[\mathrm{b}]}$ & $a(\mathrm{~N})_{\mathrm{y}}^{[\mathrm{b}]}$ & & & \\
\hline \multirow{3}{*}{$\begin{array}{c}{\left[\mathrm{Ni}\left(\mathrm{Cl}_{4} \text { saltrien }\right)\right]^{+}} \\
\text {(4) }\end{array}$} & \multirow{3}{*}{$\begin{array}{c}\left.{ }^{14} \mathrm{~N}\right] \text { pyridine } \\
\mathrm{CN}^{-} \\
{ }^{13} \mathrm{CN}^{-}\end{array}$} & 2.205 & 2.093 & 2.063 & 2.120 & \multirow[t]{3}{*}{1.10} & \multirow[t]{3}{*}{2.00} & \multirow[t]{3}{*}{2.00} & & & \\
\hline & & 2.177 & 2.142 & 2.021 & 2.113 & & & & & & \\
\hline & & 2.177 & 2.141 & 2.021 & 2.113 & & & & & & \\
\hline \multirow{4}{*}{${ }_{(3)}^{[\mathrm{Ni}(\text { naptrien })]^{+}}$} & {$\left[{ }^{14} \mathrm{~N}\right]$ pyridine } & 2.214 & 2.096 & 2.050 & 2.120 & \multirow{4}{*}{$\begin{array}{l}1.10 \\
1.05\end{array}$} & 1.70 & 1.70 & & & \\
\hline & {$\left[{ }^{15} \mathrm{~N}\right]$ pyridine } & 2.212 & 2.094 & 2.050 & 2.118 & & \multirow[t]{3}{*}{1.70} & \multirow[t]{3}{*}{1.70} & & & \\
\hline & $\mathrm{CN}^{-}$ & 2.162 & 2.147 & 2.019 & 2.109 & & & & & & \\
\hline & ${ }^{13} \mathrm{CN}^{-}$ & 2.165 & 2.149 & 2.020 & 2.111 & & & & & & \\
\hline
\end{tabular}

[a] The value of $g_{\mathrm{av}}$ was calculated as $\left(g_{x}+g_{y}+g_{z}\right) / 3 .-{ }^{[\mathrm{b}]} a(\mathrm{~N})$ values are expressed in $\mathrm{mT}$.

to interpret the spectra, we made use of ${ }^{13} \mathrm{CN}^{-}$and found that the EPR spectra of the enriched adducts are identical to those with natural abundance $\mathrm{CN}^{-}$(Figure 2, F, and Figure 3, F): a clear indication that no direct spin interaction of the nickel unpaired electron with the carbon atom of the cyanide ion takes place. Furthermore, we note that the spectrum of $\left[\mathrm{Ni}^{\mathrm{III}}(\mathrm{CN})_{6}\right]^{3-}$ is completely different from those reported here, ${ }^{[26]}$ which implies that displacement of the pentadentate ligand by cyanide ions had not taken place.

The number of bound cyanide ions could not be determined, and the complexes may thus be formulated as [ $\mathrm{Ni}^{\mathrm{III}}$ $(\mathrm{L})(\mathrm{CN})]$ or, if the cyanide ions replace the solvent molecule and the $\mathrm{N}$ (amine) group, as $\left[\mathrm{Ni}^{\mathrm{III}}(\mathrm{L})(\mathrm{CN})_{2}\right]^{-1}$. However, the latter hypothesis gained some support by the large hypsochromic shift (stronger ligand field) in the d-d transitions, relative to those of the nickel(III) precursor complexes, observed upon cyanide coordination.

Before attempting to interpret the EPR spectra of the cyanide adducts, we must stress that, for all the other $\mathrm{Ni}^{\mathrm{III}}$ species referred to above, the equatorial plane was defined by the ligand $\left\{\left[\mathrm{N}_{2}\right.\right.$ (imine) $\left.\left.\mathrm{O}_{2}\right]\right\}$ atoms and the molecular $z$ axis was the $\left[\mathrm{N}(\right.$ amine $\left.)-\mathrm{Ni}^{\mathrm{III}}-\mathrm{X}\right]$ axis $(\mathrm{X}=$ solvent or py) (Scheme 3 and Scheme 4).

\section{Complexes with trien Bridge Ligands}

The recognition that the spectra are unambiguously attributable to an axially elongated $\mathrm{d}_{z^{2}}$ ground state and the non-observation of hyperfine splitting in any of the three $g$ regions indicate that neither the cyanide ions $\left({ }^{13} \mathrm{CN}^{-}\right)$nor any nitrogen atom interacts directly with the unpaired electron in the $\mathrm{d}_{z}{ }^{2}$ orbital. Consequently, the oxygen atoms of the pentadentate ligand must occupy the axial positions. The $z$ axis must be the $\left[\mathrm{O}-\mathrm{Ni}^{\mathrm{III}}-\mathrm{O}\right]$ axis, with the two cyanide ions and the two $\mathrm{N}$ (imine) atoms defining the equatorial plane. This arrangement is only possible if the polydentate ligand retains the trans configuration of the nickel(II) parent complex (Scheme 3). The ligand field in the $\left[\mathrm{CN}^{-}-\mathrm{Ni}^{\mathrm{III}}-\mathrm{CN}^{-}\right]$direction is very strong and weakens the ligand field in the perpendicular plane, which makes the $\left[\mathrm{O}-\mathrm{Ni}^{\mathrm{III}}-\mathrm{O}\right]$ bonds longer. A precedent for this proposal is provided by studies on the interaction of cyanide ions with tripeptide complexes of $\mathrm{Ni}^{\mathrm{III}}$, for which a change in molecular axis has also been observed upon ligation of cyanide ions. ${ }^{[26-28]}$

\section{Complexes with Metrien Bridge Ligands}

The key difference in the EPR spectra of Metrien derivatives is the observation of hyperfine splittings in $g_{z}$. As identical spectra were observed for ${ }^{12} \mathrm{CN}^{-}$and ${ }^{13} \mathrm{CN}^{-}$, the cyanide ions cannot be considered as the origin for the observed splitting. The atoms causing the observed splittings must be the nitrogen atoms of the polydentate ligand, ${ }^{14} \mathrm{~N}(I=1)$. The only explanation for the observed multiplet is to assume that the spectra of Metrien derivatives are the superimposition of two spectra: (i) one without any hyperfine splitting and which is similar to those of the trien derivatives, and (ii) the other, which exhibits a 1:1:1 triplet in the $g_{z}$ region $(a=2.00-2.10 \mathrm{mT})$. The former spectra must correspond to species with the same configuration as those 
of $\left[\mathrm{Ni}^{\mathrm{III}}(\mathrm{L})(\mathrm{CN})_{2}\right]^{-1}$ (with $\mathrm{L}=$ naptrien, $\mathrm{Cl}_{4}$ saltrien), with the polydentate ligand in a trans conformation. The latter spectra can be accounted for by assuming that the same change in the $z$ axis has occurred, but with the $z$ axis defined by one imine nitrogen atom and one oxygen atom of the polydentate ligand, which implies a cis configuration for the polydentate ligand (Scheme 4).

\section{Conclusions}

The accessibility of the +3 oxidation state in the nickel(II) complexes $\mathbf{1 - 6}$ is determined primarily by the binding or non-binding of the polydentate ligand amine nitrogen atom to the metal centre, which in turn depends on the number of carbon atoms in the imine bridge. Complexes with dien bridges are irreversibly oxidised in all solvents, under the experimentally used cyclic voltammetric conditions, whereas complexes with trien/Metrien-based ligands show quasi-reversible processes. In the former, steric constraints prevent coordination of the amine nitrogen atom to $\mathrm{Ni}^{\mathrm{II}}$, thus enforcing a tetradentate coordination mode for the ligand, but with trien/Metrien bridges the ligand enforces a true $\mathrm{N}_{3} \mathrm{O}_{2}$ pentadentate coordination sphere.

Formation of nickel(III) complexes takes place with the simultaneous increase of the coordination number to 6 , by binding of solvent molecules. Analysis of EPR spectra has permitted unambiguous identification of the oxidised species. Spectra of oxidized trien/Metrien-based complexes are anisotropic, with a ${ }^{2} \mathrm{~A}_{1}$ ground state $(a \geq b)$, and provide direct evidence for coordination of the imine bridge nitrogen atom. On the other hand, chemically oxidised dienbased complexes in DMF and $\left(\mathrm{CH}_{3}\right)_{2} \mathrm{SO}$ exhibit quasi-axial spectra with a ${ }^{2} \mathrm{~A}_{1}$ ground state $(a>>b)$ and no hyperfine couplings, which indicates that the amine nitrogen atom is not coordinated. The difference in stability of dien- and trien/Metrien-based complexes is thus attributable to the binding of the bridging amine nitrogen atom. With one axial coordination position occupied by a strong donor (the ligand amine nitrogen atom), the stabilization of species oxidised at the metal centre is less sensitive to the coordination ability of the solvent molecule bound to the other axial position.

The stability of the $\mathrm{Ni}^{\mathrm{III}}$ trien/Metrien-based complexes has prompted the study of the interaction of these complexes with pyridine and cyanide ion, ligands of increasing ligand strength. EPR data have made it clear that these polydentate ligands provide a flexible coordination sphere, and that by varying the equatorial/axial ligand field ratio it is possible to obtain $\mathrm{Ni}^{\mathrm{III}}$ species in three different ground states. Furthermore, it has become evident that the ground state of $\mathrm{Ni}^{\mathrm{III}}$ species is also dependent on the substituents on the imine bridge nitrogen atom: $-\mathrm{H}$ (trien) or $-\mathrm{CH}_{3}$ (Metrien).

For pyridine adducts of Metrien-based complexes, a ground state similar to that of the parent $\mathrm{Ni}^{\mathrm{III}}$ complex, with ${ }^{2} \mathrm{~A}_{1}$ and $a \geq b$, was obtained, whereas for trien-based complexes an inverted ground state, ${ }^{2} \mathrm{~A}_{1}$, was observed, with $a<<b$. The different behaviour was attributed to the stronger axial field induced by the unsubstituted amine nitrogen in the imine bridge, as compared with Metrien, which, when combined with the ligand strength of pyridine, is enough to invert the magnitude of the contribution of the two $\mathrm{d}$ orbitals defining the ${ }^{2} \mathrm{~A}_{1}$ ground state.

Upon addition of cyanide $\left({ }^{13} \mathrm{CN}^{-}\right.$and natural abundance $\mathrm{CN}^{-}$), a more drastic change in the ground state was observed. The rhombic spectra of the parent complexes changed to axial EPR spectra, typical of complexes with a ground state that is formulated as ${ }^{2} \mathrm{~A}_{1}$, with $a>>b$. Combining this result with the non-observation of any hyperfine splitting in trien-based complexes, we propose that the strong ligand field of cyanide ions causes a shortening of the $\mathrm{Ni}-\mathrm{C}$ bond lengths, so as to change the principal molecular axis of $\mathrm{Ni}^{\mathrm{III}}$ complexes, but in which the ligand exists in a trans conformation. For Metrien-based complexes, similar spectra have been observed, but with hyperfine splittings in the high magnetic field region. The same changes in the principal molecular axis are assumed, but analysis of the hyperfine splitting pattern has prompted us to propose the existence of $\mathrm{Ni}^{\mathrm{III}}$ complexes in which the ligands exist in trans and cis conformations, probably a consequence of the steric requirements of the amine nitrogen methyl group.

\section{Experimental Section}

Reagents and Solvents: Solvents and reagents for synthesis were obtained from commercial sources and used as received. The solvents used in electrochemistry were from Merck (pro analysi). Pyridine and potassium cyanide were from Merck (p.a.). $\left[{ }^{15} \mathrm{~N}\right]$ Pyridine was purchased from Cambridge Isotope Laboratories and potassium $\left[{ }^{13} \mathrm{C}\right]$ cyanide from Aldrich. Tetraethylammonium perchlorate $\left(\mathrm{NEt}_{4}{ }^{-}\right.$ $\mathrm{ClO}_{4}$ ) was prepared by published procedures ${ }^{[29]}$ from the bromide salt (Aldrich) and perchloric acid (Merck, p.a.).

CAUTION: Perchlorates are hazardous and may explode.

Synthesis of Ligands and Nickel(II) Complexes: The ligands $\mathrm{H}_{2}$ napdien (bis $\{2-[(2-h y d r o x y n a p h t h y l) m e t h y l i m i d o] e t h y l\}$ amine $), \mathrm{H}_{2}$ naptrien (bis $\{3-[(2-h y d r o x y n a p h t h y l) m e t h y l i m i d o] p r o p y l\}$ amine), $\mathrm{H}_{2}$ napMetrien (bis $\{3-[(2-h y d r o x y n a p h t h y l) m e t h y l i m i d o] p r o p y l\}-$ (methyl)amine), $\mathrm{H}_{2} \mathrm{Cl}_{4}$ saldien $\{$ bis[2-(3,5-dichlorosalicylimido)ethyl]amine\}, $\mathrm{H}_{2} \mathrm{Cl}_{4}$ saltrien \{bis[3-(3,5-dichlorosalicylimido)propyl]amine\}, and $\mathrm{H}_{2} \mathrm{Cl}_{4}$ salMetrien $\{$ bis[3-(3,5-dichlorosalicylimido)propyl](methyl)amine\} were prepared by standard methods. ${ }^{[12,17]}$ Typically, the triamine [bis(2-aminoethyl)amine, bis(3-aminopropyl)amine or bis(3-aminopropyl)(methyl)amine] $(0.01 \mathrm{~mol})$ was added directly to a warm ethanolic solution of the aldehyde (naphthaldehyde and 3,5-dichlorosalicylaldehyde) (0.02 $\mathrm{mol}$ ); the reaction mixture was heated to reflux for $30 \mathrm{~min}$ and then cooled on ice. The compounds $\mathrm{H}_{2}$ napdien, $\mathrm{H}_{2} \mathrm{Cl}_{4}$ saldien and $\mathrm{H}_{2}$ naptrien precipitated from the solution, yielding yellow solids that were recrystallised from methanol; the other ligands were obtained as brown/yellow oils, after solvent removal.

$\mathrm{H}_{2}$ napdien: Yield: $3.7 \mathrm{~g}(90 \%)$. $-\mathrm{C}_{26} \mathrm{H}_{25} \mathrm{~N}_{3} \mathrm{O}_{2}$ (411.5): calcd. $\mathrm{C}$ 75.89, H 6.12, N 10.21; found $\mathrm{C} 75.80, \mathrm{H} 6.12, \mathrm{~N} \mathrm{10.19.}-{ }^{1} \mathrm{H}$ NMR $\left(\mathrm{CDCl}_{3}, 200 \mathrm{MHz}, 297 \mathrm{~K}\right): \delta=2.88-3.69\left(8 \mathrm{H}, \mathrm{CH}_{2}\right)$, 6.68-8.02 (12 H, aromatic H), $9.06(2 \mathrm{H}, \mathrm{N}=\mathrm{CH}), 13.91(2 \mathrm{H}$, $\mathrm{OH})$. 
$\mathrm{H}_{2}$ naptrien: Yield: $3.0 \mathrm{~g}(68 \%) .-\mathrm{C}_{28} \mathrm{H}_{29} \mathrm{~N}_{3} \mathrm{O}_{2} \cdot 5 /{ }_{2} \mathrm{H}_{2} \mathrm{O}$ (484.6): calcd. C 69.40, H 7.07, N 8.67; found C 69.27, H 7.00, N 8.66. ${ }^{1} \mathrm{H} \mathrm{NMR}\left(\mathrm{CDCl}_{3}, 200 \mathrm{MHz}, 297 \mathrm{~K}\right): \delta=1.80-3.70\left(12 \mathrm{H}, \mathrm{CH}_{2}\right)$, 6.68-8.02 $(12 \mathrm{H}$, aromatic $\mathrm{H}), 9.06(2 \mathrm{H}, N=C H), 13.95(2 \mathrm{H}$, $\mathrm{OH})$.

$\mathbf{H}_{2}$ napMetrien: Yield: $3.2 \mathrm{~g}(70 \%)$, obtained as an oil. $-{ }^{1} \mathrm{H}$ NMR $\left(\mathrm{CDCl}_{3}, 200 \mathrm{MHz}, 297 \mathrm{~K}\right): \delta=2.20\left(3 \mathrm{H}, \mathrm{CH}_{3}\right), 1.85-3.69(12 \mathrm{H}$, $\left.\mathrm{CH}_{2}\right), 6.69-8.03(12 \mathrm{H}$, aromatic $\mathrm{H}), 9.01(2 \mathrm{H}, \mathrm{N}=\mathrm{CH}), 14.02(2$ $\mathrm{H}, \mathrm{OH})$.

$\mathbf{H}_{2} \mathbf{C l}_{4}$ saldien: Yield: $4.2 \mathrm{~g}(93 \%) .-\mathrm{C}_{18} \mathrm{H}_{17} \mathrm{Cl}_{4} \mathrm{~N}_{3} \mathrm{O}_{2}$ (449.2): calcd. $\mathrm{C} 46.03, \mathrm{H} 3.86, \mathrm{~N} 7.67$; found $\mathrm{C} 45.97, \mathrm{H} 3.84, \mathrm{~N} 7.68 .-{ }^{1} \mathrm{H}$ NMR $\left(\mathrm{CDCl}_{3}, 200 \mathrm{MHz}, 297 \mathrm{~K}\right): \delta=2.70-2.82\left(8 \mathrm{H}, \mathrm{CH}_{2}\right)$, 7.09-7.38 (4 H, aromatic $\mathrm{H}), 8.23(2 \mathrm{H}, \mathrm{N}=\mathrm{CH})$.

$\mathbf{H}_{\mathbf{2}} \mathbf{C l}_{4}$ saltrien: Yield: $3.5 \mathrm{~g}(74 \%)$, obtained as oil. $-{ }^{1} \mathrm{H}$ NMR $\left(\mathrm{CDCl}_{3}, 200 \mathrm{MHz}, 297 \mathrm{~K}\right): \delta=1.85-2.80\left(12 \mathrm{H}, \mathrm{CH}_{2}\right), 7.10-7.38$ (4 $\mathrm{H}$, aromatic $\mathrm{H}), 9.86(2 \mathrm{H}, \mathrm{N}=\mathrm{CH})$.

$\mathbf{H}_{2} \mathbf{C l}_{4}$ salMetrien: Yield: $3.4 \mathrm{~g}(72 \%)$, obtained as oil. $-{ }^{1} \mathrm{H}$ NMR $\left(\mathrm{CDCl}_{3}, 200 \mathrm{MHz}, 297 \mathrm{~K}\right): \delta=2.20\left(3 \mathrm{H}, \mathrm{CH}_{3}\right), 1.86-2.44(12 \mathrm{H}$, $\left.\mathrm{CH}_{2}\right), 7.08-7.38(4 \mathrm{H}$, aromatic $\mathrm{H}), 8.21(2 \mathrm{H}, \mathrm{N}=\mathrm{CH})$

The nickel(II) complexes were also synthesised by standard procedures; ${ }^{[12,17]}$ typically, ethanolic solutions of the ligands $(5 \mathrm{mmol})$ were added to ethanolic nickel(II) acetate solutions ( $5 \mathrm{mmol}$ ); the resulting solutions were heated to reflux for $60 \mathrm{~min}$. Upon cooling, green solids were collected by filtration, recrystallised from acetonitrile (except for dien-based complexes), and dried under vacuum for several hours.

[Ni(napdien)] (1): Yield: $1.7 \mathrm{~g}(72 \%) .-\mathrm{C}_{26} \mathrm{H}_{23} \mathrm{~N}_{3} \mathrm{NiO}_{2}$ (468.2): calcd. C 75.89, H 6.12, N 10.21; found C 75.36, H 6.12, N 10.11 . - UV/Vis: $\lambda_{\max } / \mathrm{nm}\left(\varepsilon / \mathrm{dm}^{3} \mathrm{~mol}^{-1} \mathrm{~cm}^{-1}\right)=402$ (6600), $420 \mathrm{sh}$ (DMF).

[Ni(naptrien)] (3): Yield: $1.5 \mathrm{~g}(60 \%) .-\mathrm{C}_{28} \mathrm{H}_{27} \mathrm{~N}_{3} \mathrm{NiO}_{2}$ (496.3): calcd. C 67.77, H 5.48, N 8.47; found C 67.59, H 5.48, N 8.62. UV/Vis: $\lambda_{\max } / \mathrm{nm}\left(\varepsilon / \mathrm{dm}^{3} \mathrm{~mol}^{-1} \mathrm{~cm}^{-1}\right)=1143$ (39), 1010 (33), 566 (85), 521 sh, 408 (9700), 389 (11300) (DMF); $\lambda_{\max } / \mathrm{nm}=606,522$ sh, 418 (Nujol).

[Ni(napMetrien)] (5): Yield: $1.8 \mathrm{~g}(68 \%) .-\mathrm{C}_{29} \mathrm{H}_{29} \mathrm{~N}_{3} \mathrm{NiO}_{2}$ (510.3): calcd. C 68.26, H 5.73, N 8.23; found C 68.79, H 5.72, N 8.17. UV/Vis: $\lambda_{\max } / \mathrm{nm}\left(\varepsilon / \mathrm{dm}^{3} \mathrm{~mol}^{-1} \mathrm{~cm}^{-1}\right)=1200(20), 1013(10), 570$ (63), $521 \mathrm{sh}, 408$ (10000), 388 (11900) (DMF); $\lambda_{\max } / \mathrm{nm}=584,524$ sh, 418 (Nujol).

[Ni(Cl $\mathbf{C l}_{4}$ saldien)] (2): Yield: $1.9 \mathrm{~g} \quad(75 \%) . \quad-\mathrm{C}_{18} \mathrm{H}_{15} \mathrm{Cl}_{4} \mathrm{~N}_{3} \mathrm{NiO}_{2}$ (505.9): calcd. C 48.13, H 3.81, N 9.36; found C 48.97, H 3.82, N 9.39. - UV/Vis: $\lambda_{\max } / \mathrm{nm}\left(\varepsilon / \mathrm{dm}^{3} \mathrm{~mol}^{-1} \mathrm{~cm}^{-1}\right)=419$ (5300), 450 sh (DMF).

[Ni(Cl 4 saltrien)] (4): Yield: $1.4 \mathrm{~g}(53 \%) .-\mathrm{C}_{20} \mathrm{H}_{19} \mathrm{Cl}_{4} \mathrm{~N}_{3} \mathrm{NiO}_{2} \cdot 2 \mathrm{H}_{2} \mathrm{O}$ (533.9): calcd. C 42.15, H 4.07, N 7.37; found C 42.27, H 4.00, N 7.55. - UV/Vis: $\lambda_{\max } / \mathrm{nm}\left(\varepsilon / \mathrm{dm}^{3} \mathrm{~mol}^{-1} \mathrm{~cm}^{-1}\right)=1088(10), 935(11)$, 564 (30), 384 (8500) (DMF); $\lambda_{\max } / \mathrm{nm}=564,386$ (Nujol).

[Ni(Cl 4 salMetrien)] (6): Yield: $1.5 \mathrm{~g}(57 \%) .-\mathrm{C}_{21} \mathrm{H}_{21} \mathrm{Cl}_{4} \mathrm{~N}_{3} \mathrm{NiO}_{2}$ (547.9): calcd. C 46.03, H 3.86, N 7.67; found C 45.98, H 3.84, N 7.68. - UV/Vis: $\lambda_{\max } / \mathrm{nm}\left(\varepsilon / \mathrm{dm}^{3} \mathrm{~mol}^{-1} \mathrm{~cm}^{-1}\right)=1159$ (8), $966(10)$, 568 (36), 381 (10100) (DMF); $\lambda_{\max } / \mathrm{nm}=590,392$ (Nujol).

Preparation of the Nickel(III) Complexes and Adduct Formation: Nickel(III) complexes were generated electrochemically by exhaustive electrolysis of DMF solutions $10^{-3} \mathrm{~mol} \cdot \mathrm{dm}^{-3}$ in nickel(II) precursor and $0.1 \mathrm{~mol} \cdot \mathrm{dm}^{-3}$ in $\mathrm{NEt}_{4} \mathrm{ClO}_{4}$ at ca. $4{ }^{\circ} \mathrm{C}$. The time elap- sing during the electrolysis was varied from 20 to $45 \mathrm{~min}$; the upper limit was chosen to avoid extensive decomposition of the oxidised species. Chemically oxidised nickel(III) species were obtained by addition of a large excess (ca. 50\%) of iodine to solutions of the nickel(II) precursors. Because of the instability of the electrogenerated $\mathrm{Ni}^{\mathrm{III}}$ species it was not possible to isolate solids, and so these species were generated shortly before measurements and kept frozen in liquid nitrogen. The decay of $\mathrm{Ni}^{\mathrm{III}}$ species is significantly lessened at low temperatures, and the samples are stable for several days when kept in liquid nitrogen. The adducts were prepared at temperatures just above the softening point of the frozen glass, by addition of freshly electrolysed solution of nickel(III) to frozen solutions or suspensions of the corresponding bases.

Physical Measurements: Elemental analysis (C, H, and N) were performed at the Departmento de Química, Faculdade de Ciências, Universidade do Porto. - Electrochemical measurements were made with a PAR 273 potentiostat, using solutions ca. $10^{-3}$ $\mathrm{mol} \cdot \mathrm{dm}^{-3}$ in nickel(II) complex and $0.1 \mathrm{~mol} \cdot \mathrm{dm}^{-3}$ in $\mathrm{NEt}_{4} \mathrm{ClO}_{4} \cdot-$ Cyclic voltammetry was performed in $\mathrm{MeOH}$, DMF, and $\mathrm{Me}_{2} \mathrm{SO}$, using a platinum microsphere as working electrode, a platinum wire as counter-electrode, and an $\mathrm{Ag} / \mathrm{AgCl}\left(1 \mathrm{~mol} \cdot \mathrm{dm}^{-3} \mathrm{NaCl}\right)$ reference electrode. All potentials are reported relative to that of the reference electrode and to $E_{1 / 2}$ of the ferrocenium/ferrocene couple; under the experimental conditions used, $E_{1 / 2}$ for the latter couple is $0.48 \mathrm{~V}$ in $\mathrm{Me}_{2} \mathrm{SO}, 0.47 \mathrm{~V}$ in $\mathrm{DMF}$ and $0.45 \mathrm{~V}$ in $\mathrm{MeOH}$. Scan rates from 0.05 to $0.50 \mathrm{~V} \cdot \mathrm{s}^{-1}$ were used, and the low and high potential limits were $0.00 \mathrm{~V}$ and $1.20 \mathrm{~V}$. - Electrolyses in DMF were carried out at controlled potential, at values about $0.10 \mathrm{~V}$ higher than the anodic peak potential in a three-electrode cell, using platinum gauze as working and counter-electrodes, and an $\mathrm{Ag} / \mathrm{AgCl}$ (1 $\mathrm{mol} \cdot \mathrm{dm}^{-3} \mathrm{NaCl}$ ) reference electrode (all from Metrohm). - Electronic spectra were recorded with a Shimadzu UV 3101PC spectrophotometer, in the range $1500-300 \mathrm{~nm}$. Conditions used were: room temperature, $10^{-2}$ and $10^{-4} \mathrm{~mol} \cdot \mathrm{dm}^{-3}$, for nickel(II) complexes; and temperature about $4{ }^{\circ} \mathrm{C}$ and $10^{-3} \mathrm{~mol} \cdot \mathrm{dm}^{-3} \mathrm{Ni}^{\mathrm{II}}$ solutions for chemically and electrolysed $\mathrm{Ni}^{\mathrm{III}}$ complexes. - EPR spectra were obtained at $77 \mathrm{~K}$ with a Bruker ESP 300E X-band spectrometer, using an insert Dewar. The magnetic field was calibrated by using $\mathrm{Mn}^{2+}$ in $\mathrm{MgO}$, and diphenylpicrylhydrazyl was used as internal reference $(\mathrm{dpph} ; g=2.0037)$. The reported EPR parameters were obtained by spectral simulation using the programme WinEPR Simfonia (Bruker) and assuming rhombic Spin Hamiltonians; line widths were typically in the range $1.5-2.0(z)$ to $1.5-3.0$ $(x, y) \mathrm{mT}$. The values of $a(\mathrm{~N})_{x, y}$ are less accurate, due to the low spectral resolution. Typical experimental conditions used: microwave power $10-15 \mathrm{~mW}$; modulation amplitude $0.5 \mathrm{mT}$; modulation frequency $100 \mathrm{kHz}$.

\section{Acknowledgments}

This work was partially supported by the "Fundação para a Ciência e Tecnologia" (Lisboa) through project Praxis/2/2.1/QUI/316/ 94.

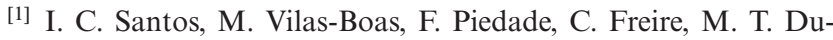
arte, B. de Castro, Polyhedron 2000, 19, 655-664.

${ }^{[2]}$ C. Freire, B. de Castro, Polyhedron 1998, 17, 4227-4235.

[3] C. Freire, B. de Castro, J. Chem. Soc., Dalton Trans. 1998 1491-1497.

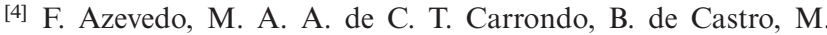
Convery, D. Domingues, C. Freire, M. T. Duarte, K. Nielson, I. Santos, Inorg. Chim. Acta 1994, 219, 43-54. 
[5] M. A. A. de C. T. Carrondo, B. de Castro, A. M. Coelho, D. Domingues, C. Freire, J. Morais, Inorg. Chim. Acta 1993, 205, 157-166.

[6] C. Freire, B. de Castro, Inorg. Chem 1990, 29, 5113-5119.

[7] M. Vilas-Boas, C. Freire, B. de Castro, P. A. Christensen, A. R. Hillman, Inorg. Chem. 1997, 36, 4919-4929.

${ }^{[8]}$ M. Vilas-Boas, C. Freire, B. de Castro, A. R. Hillman, J. Phys. Chem. B 1998, 102, 8533-8540.

[9] F. Azevedo, C. Freire, B. de Castro, manuscript in preparation.

${ }^{[10]}$ C. Gosden, J. B. Kerr, D. Pletcher, R. Rosas, J. Electroanal. Chem. Interfacial Electrochem. 1981, 117, 101-107.

${ }^{[11]}$ C. Freire, B. de Castro, E. Pereira, J. Chem. Soc., Dalton Trans. 1994, $571-576$.

${ }^{[12]}$ W. M. Coleman, L. T. Taylor, Inorg. Chem. 1971, 10, 2195-2199.

${ }^{[13]}$ E. M. Boge, D. P. Freyberg, E. Kokot, G. M. Mockler, E. Sinn, Inorg. Chem. 1977, 16, 1655-1660.

${ }^{[14]}$ M. Nemiroff, S. L. Holt, Inorg. Chem. 1973, 12, 2032-2037.

${ }^{[15]}$ L. Taylor, W. M. Coleman, J. Am. Chem. Soc. 1970, 92, $1449-1450$.

[16] L. Gomes,D. Pinho, C. Freire, B. de Castro, Acta Crystallogr. 1999, C55, 1425-1427.

${ }^{[17]}$ L. Sacconi, I. Bertini, J. Am. Chem. Soc. 1966, 88, 5180-5185.
${ }^{[18]}$ A. J. Bard, L. R. Faulkner, Electrochemical methods, Wiley, New York, 1980.

${ }^{[19]}$ P. Zanello, R. Cini, A. Cinquanti, Inorg. Chim. Acta 1983, 74, 89-95.

${ }^{[20]}$ J. H. Cameron, K. J. Mcullough, J. Chem. Soc., Dalton Trans. 1990, 935-941.

[21] B. R. McGarvey, Can. J. Chem. 1975, 53, 2498-2511.

${ }^{[22]}$ A. H. Maki, N. Edelstein, A. Daveson, R. H. Holm, J. Am. Chem. Soc. 1964, 86, 4580-4587.

${ }^{[23]}$ C. Daul, C. W. Schlapfer, A. van Zeleewsky, Struct. Bonding (Berlin) 1979, 36, 129.

[24] P. J. Chmielewski, L. Latos-Graazynski, Inorg. Chem. 1997, $36,840-845$.

${ }^{[25]}$ H.-J. Kruger, R. H. Holm, Inorg. Chem. 1989, 28, 1148-1155.

${ }^{[26]} \mathrm{S}$. Chandrasekhar, A. McAuley, Inorg. Chem. 1992, 31, 2234-2240.

[27] T. L. Pappenhagen, D. W. Margerum, J. Am. Chem. Soc. 1985, 197, 4576-4577.

${ }^{[28]}$ Y. L. Wang, M. W. Beach, T. L. Pappenhagen, D. W. Margerum, Inorg. Chem. 1988, 27, 4464-4472.

${ }^{[29]}$ S. T. Donald, Jr., R. L. Julien, Experimental Electrochemistry for Chemistry, John Wiley \& Sons, New York, 1988.

Received October 9, 2000

[I00377] 